\title{
Global dynamics of humoral and cellular immune responses to virus infection
}

\author{
Miller Cerón Gómez ${ }^{1, *}$, Hyun Mo Yang ${ }^{2}$
}

\section{Edited by}

Juan Carlos Salcedo-Reyes

(salcedo.juan@javeriana.edu.co)

1. Universidad de Nariño, Torobajo, Calle 18 Carrera 50, Pasto - Colombia.

2. Universidade Estadual de Campinas, Cidade Universitária "Zeferino Vaz" CEP 13083-970, Campinas - Brasil.

* millercg@udenar.edu.co

Received: 09-10-2018

Accepted: 24-05-2019

Published on line: 31-07-2019

Citation: Cerón Gómez M, Yang HM. Global dynamics of humoral and cellular immune responses to virus infection, Universitas Scientiarum, 24 (2): 407-423, 2019. doi: 10.11144/Javeriana.SC24-2.gdoh

\section{Funding:}

N.A.

Electronic supplementary material: Suppl. 1.

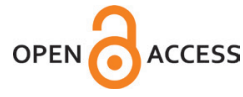

\begin{abstract}
We study the global stability of a model of virus dynamics with consideration of humoral and cellular immune responses. We use a Lyapunov direct method to obtain sufficient conditions for the global stability of virus-free and viruspresence equilibriums. First, we analyze the model without an immune response and found that if the reproductive number of the virus is less than or equal to one, the virus-free equilibrium is globally asymptotically stable. However, for the virus-presence equilibrium, global stability is obtained if the virus entrance rate into the target cells is less than one. We analyze the model with humoral and cellular immune responses and found similar results. The difference is that in the reproductive number of the virus and in the virus entrance rate into the target cells appear parameters of humoral and cellular immune responses, which means that the adaptive immune response will cease or control the rise of the infection.
\end{abstract}

Keywords: global stability; immune response; Lyapunov direct method.

\section{Introduction}

Global stability analysis in models of within-host viral infections has been addressed in particular cases. In [1], the authors proved global stability by using an extension of the Poincaré-Bendixson theorem for the class of threedimensional competitive systems. In [2], the authors used the direct Lyapunov method to demonstrate global stability. The same was done in a model with a Beddington-DeAngelis functional response [3]. In [4], the authors proved global stability of a model considering general nonlinear incidence rate, cure rate and absorption. In [5], the authors proved global stability of an agestructured viral infection model with general incidence rate and absorption. 
On the other hand, there are models (see [6-9]) that consider the immune response with global stability analysis. All of those models study humoral or cellular immune response or both. A model considering humoral, cellular immune response and a general incidence rate is presented in [10], which generalized all the models mentioned before. But this model did not consider the virus absorption by target cells, that is, when the virus penetrates in the cells, this amount must be diminished. In this sense, our model, besides including the humoral and cellular immune responses, takes into account the virus entrance rate into the target cells. Initially, using a direct Lyapunov method, we show the global stability of a model of virus dynamics without immune response. Further, we obtain conditions for the global stability of the model considering humoral and cellular immune responses. The organization of this paper is as follows. In Section 2, we present the formulation of the model with immune response and the positive invariant set. The global stability analysis of the model without an immune response is presented in Section 3. Finally, in Section 6, we provide the global stability analysis of the model with humoral and cellular immune responses.

\section{Model Formulation}

We denote by $S, I, V, B$ and $T$ the target cells, infected cells, dengue virus, $\mathrm{B}$ cells and the cytotoxic T cells, respectively. The $S$ cells are produced in bone marrow at a constant rate $k_{s}$. The target cells are chronically infected at rate $\beta_{I}$ and die at a rate $\mu_{s}$, the lysis of these infected cells occur by action of the cytotoxic CD8+ cells $T$ at rate $\alpha_{I}$, and die by apoptosis at rate $\mu_{I}$. We assume that cytotoxic $\mathrm{T}$ cells are responsible for cellular immune response, that is, to eliminate the intracellular pathogens (kill the infected cells) and that the $\mathrm{B}$ cells are responsible for humoral immune response, i.e., to defend the host from extracellular pathogens. We consider that $\mathrm{B}$ cells and cytotoxic $\mathrm{T}$ cells are produced in the bone marrow at rate $k_{B}$ and $k_{T}$, and the diverse chemical signals will activate $B$ cells and cytotoxic $T$ cells. However, these cells, in the beginning of this activation, do not have high affinity, which means that they are not efficient to clear the virus infection, so by somatic hypermutations, they become step by step with better affinity (fit) to stop or kill the virus. Therefore, the $\mathrm{B}$ cells are going to proliferate in the presence of dengue virus at rate $\alpha_{B}$, and the cytotoxic T cells, by the presence of infected cells at rate $\alpha_{T}$, and have death rate $\mu_{B}$ and $\mu_{T}$, respectively. The virus amount is considered proportional to the virus released by the infected cells after their death $N_{1}\left(\mu_{s}+\mu_{I}\right) I$, where $N_{1}$ is the number of virions released by an infected cell. We assume that more than one particle of virus will try to infect each 
cell denoted by $N_{2}$, the action of antibodies against the virus is considered proportional to the amount of $\mathrm{B}$ cells at rate $\alpha_{v}$, and finally the virus decay at rate $\mu_{v}$. The differential equations describing the interaction of dengue virus and the immune system are given by

$$
\begin{aligned}
& \frac{d S}{d t}=k_{s}-\beta_{I} S V-\mu_{s} S, \\
& \frac{d I}{d t}=\beta_{I} S V-\alpha_{I} I T-\left(\mu_{s}+\mu_{I}\right) I, \\
& \frac{d V}{d t}=N_{1}\left(\mu_{s}+\mu_{I}\right) I-N_{2} \beta_{I} S V-\alpha_{v} B V-\mu_{v} V, \\
& \frac{d B}{d t}=k_{B}+\alpha_{B} B V-\mu_{B} B, \\
& \frac{d T}{d t}=k_{T}+\alpha_{T} T I-\mu_{T} T .
\end{aligned}
$$

The positively invariant set for the model (1) is given by

$$
\Omega=\left\{P \in \mathbb{R}_{+}^{5}: N_{1} S+N I+V+\frac{\alpha_{v}}{\alpha_{B}} B+\frac{N \alpha_{I}}{\alpha_{T}} T \leq \frac{k}{\delta}\right\},
$$

where $P=(S, I, V, B, T), N=\left(N_{1}+N_{2}\right), k=N_{1} k_{s}+\frac{\alpha_{v}}{\alpha_{B}} k_{B}+\frac{N \alpha_{I}}{\alpha_{T}} k_{T}$, and $\delta=\min \left\{\mu_{s}, \mu_{v}, \mu_{B}, \mu_{T}, \frac{N_{2}\left(\mu_{s}+\mu_{I}\right)}{N}\right\}$.

Lemma 2.1. The set $\Omega$ is positively invariant with respect to system (1).

Proof. Let $P_{0}=(S(0), I(0), V(0), B(0), T(0)) \in \Omega$ be the initial condition of the system (1), and $\Theta(t)$ the function defined by

$$
\Theta=N_{1} S+N I+V+\frac{\alpha_{v}}{\alpha_{B}} B+\frac{N \alpha_{I}}{\alpha_{T}} T .
$$

Taking the derivative of $\Theta$ with respect to $t$, we have:

$$
\begin{aligned}
\frac{d \Theta}{d t}=N_{1} k_{s} & -N_{1} \mu_{s} S-N_{2}\left(\mu_{s}+\mu_{I}\right) I-\mu_{v} V+\frac{\alpha_{v}}{\alpha_{B}}\left(k_{B}-\mu_{B} B\right) \\
+ & \frac{N \alpha_{I}}{\alpha_{T}}\left(k_{T}-\mu_{T} T\right),
\end{aligned}
$$

which can be written as

$$
\frac{d \Theta}{d t}+N_{1} \mu_{s} S+N_{2}\left(\mu_{s}+\mu_{I}\right) I+\mu_{v} V+\frac{\alpha_{v}}{\alpha_{B}} \mu_{B} B+\frac{N \alpha_{I}}{\alpha_{T}} \mu_{T} T=k,
$$


where $k=N_{1} k_{s}+\frac{\alpha_{v}}{\alpha_{B}} k_{B}+\frac{N \alpha_{I}}{\alpha_{T}} k_{T}$.

If we choose $\delta=\min \left\{\mu_{s}, \mu_{v}, \mu_{B}, \mu_{T}, \frac{N_{2}\left(\mu_{s}+\mu_{I}\right)}{N}\right\}$, we conclude that

$$
\frac{d \Theta}{d t} \leq k-\delta \Theta
$$

and it follows that $\frac{d \Theta}{d t} \leq 0$ if $\Theta \geq \frac{k}{\delta}$. Besides, by basic comparison theorem [11], whe have

$$
\Theta \leq \frac{k}{\delta}+\left(\Theta(0)-\frac{k}{\delta}\right) e^{-\delta t}, \quad \text { for all } t \geq 0
$$

In particular, $\Theta \leq \frac{k}{\delta}$ if $\Theta(0) \leq \frac{k}{\delta}$. Therefore, the set $\Omega$ is positively invariant. In addition, if $\Theta(0)>\frac{k}{\delta}$, then either the solution enters $\Omega$ an infinite number of times or $\Theta(t)$ approaches $\frac{k}{\delta}$ asymptotically. Hence, the set $\Omega$ attracs all solutions in $\mathbb{R}_{+}^{5}$.

In the next sections we analyze the model without immune response and the model considering humoral and cellular immune responses, given by (1).

\section{Analysis of the model without immune response}

If there is not immune response, we have the following model taking into account only the infection of target cells and the release of virus

$$
\begin{aligned}
& \frac{d S}{d t}=k_{s}-\beta_{I} S V-\mu_{s} S, \\
& \frac{d I}{d t}=\beta_{I} S V-\left(\mu_{s}+\mu_{I}\right) I, \\
& \frac{d V}{d t}=N_{1}\left(\mu_{s}+\mu_{I}\right) I-N_{2} \beta_{I} S V-\mu_{v} V .
\end{aligned}
$$

This model is a particular case of the model in [4], letting $\rho=0$ and with $f(x, y, v)=\beta_{I} S$. For this model we study the global stability of equilibrium points.

\section{Equilibrium Points for model (3)}

The virus-free equilibrium is given by $P_{0 w}=\left(\frac{k_{s}}{\mu_{s}}, 0,0\right)$, and the virus-presence equilibrium by $P_{w}=\left(S_{w}^{*}, I_{w}^{*}, V_{w}^{*}\right)$, where 


$$
S_{w}^{*}=\frac{k_{s}}{\mu_{s}} \frac{1}{R_{0}}, \quad I_{w}^{*}=\frac{k_{s}}{\left(\mu_{s}+\mu_{I}\right)}\left(1-\frac{1}{R_{0}}\right), \quad V_{w}^{*}=\frac{\mu_{s}}{\beta_{I}}\left(R_{0}-1\right),
$$

and

$$
R_{0 w}=\frac{\beta_{I}\left[N_{1}-N_{2}\right] k_{s}}{\mu_{v} \mu_{s}}
$$

\section{Global stability of virus-free equilibrium $P_{0 w}$}

Theorem 4.1. For $R_{0 w} \leq 1$, the virus-free point $P_{0 w}$ is globally asymptotically stable.

Proof. We use the direct Lyapunov method in this proof. Let $L_{1}$ be the function defined as follows $L_{1}: \Omega_{1} \rightarrow \mathbb{R}$, where

$$
\Omega_{1}=\{(S, I, V): S>0, I \geq 0, V \geq 0\},
$$

and

$$
L_{1}=\left(N_{1}-N_{2}\right) \int_{\frac{k_{s}}{\mu_{s}}}^{S} \frac{\zeta-\frac{k_{s}}{\mu_{s}}}{\zeta} d \zeta+N_{1} I+V
$$

It is easy to check that $L_{1}\left(P_{0 w}\right)=0$ and $L_{1}>0$ in $\Omega_{1}-\left\{P_{0 w}\right\}$. Besides the orbital derivative of $L_{1}$ along solutions of the system (3) is given by

$$
\begin{aligned}
\dot{L}_{1}= & \left(N_{1}-N_{2}\right)\left(1-\frac{k_{s}}{\mu_{s} S}\right)\left(k_{s}-\beta_{I} S V-\mu_{s} S\right) \\
& +N_{1}\left[\beta_{I} S V-\left(\mu_{s}+\mu_{I}\right) I\right]+\left[N_{1}\left(\mu_{s}+\mu_{I}\right) I-N_{2} \beta_{I} S V-\mu_{v} V\right],
\end{aligned}
$$

which is equivalent to

$$
\dot{L}_{1}=-\left(N_{1}-N_{2}\right) \mu_{s} S\left(1-\frac{k_{s}}{\mu_{s} S}\right)^{2}+\left(R_{0}-1\right) \mu_{v} V .
$$

From the last equation, $\dot{L}_{1}<0$ in $\Omega_{1}-\left\{P_{0 w}\right\}$ if and only if $R_{0 w} \leq 1$. Then we conclude that the virus-free point $P_{0 w}$ is globally asymptotically stable.

\section{Global stability of virus-presence equilibrium $P_{w}$}

The existence of the equilibrium $P_{w}$ is assured if $R_{0 w}>1$, and we are going to prove that $P_{w}$ is globally asymptotically stable if the virus entrance rate into the target cells is less than or equal to one, i.e., $\frac{N_{2} \beta_{I} k_{s}}{\mu_{v} \mu_{s}} \leq 1$. For this purpose, we define the function $L_{2}: \mathbb{R}_{+}^{3} \rightarrow \mathbb{R}$, where

$$
L_{2}=\left(N_{1}-N_{2}\right) \int_{S_{w}^{*}}^{S} \frac{\zeta-S_{w}^{*}}{\zeta} d \zeta+N_{1} \int_{I_{w}^{*}}^{I} \frac{\zeta-I_{w}^{*}}{\zeta} d \zeta+\int_{V_{w}^{*}}^{V} \frac{\zeta-V_{w}^{*}}{\zeta} d \zeta .
$$


This type of function was proposed by Goh in [12].

Theorem 5.1. The virus-presence equilibrium $P_{w}$ is globally asymptotically stable if

$$
\frac{N_{2} \beta_{I} k_{s}}{\mu_{v} \mu_{s}} \leq 1
$$

Remark 1. The conditions $R_{0 w}>1$ and $\frac{N_{2} \beta_{I} k_{s}}{\mu_{v} \mu_{s}} \leq 1$ give us a threshold for the parameter $\beta_{I}: \beta_{I}^{*}<\beta_{I} \leq \beta_{I}^{* *}$, where $\beta_{I}^{*}=\frac{\mu_{v} \mu_{s}}{\left[N_{1}-N_{2}\right] k_{s}}$ and $\beta_{I}^{* *}=\frac{\mu_{v} \mu_{s}}{N_{2} k_{s}}$.

Proof. First we start the proof showing that the orbital derivative of function $L_{2}$ is negative in $\mathbb{R}_{+}^{3}-\left\{P_{w}\right\}$. Taking the derivative of function $L_{2}$ along trajectories of system (3), we have

$$
\begin{aligned}
\dot{L}_{2}= & \left(N_{1}-N_{2}\right)\left(1-\frac{S_{w}^{*}}{S}\right)\left(k_{s}-\beta_{I} S V-\mu_{s} S\right) \\
& +N_{1}\left(1-\frac{I_{w}^{*}}{I}\right)\left[\beta_{I} S V-\left(\mu_{s}+\mu_{I}\right) I\right] \\
& +\left(1-\frac{V_{w}^{*}}{V}\right)\left[N_{1}\left(\mu_{s}+\mu_{I}\right) I-N_{2} \beta_{I} S V-\mu_{v} V\right] .
\end{aligned}
$$

From the equilibrium equations, we have

$$
k_{s}=\beta_{I} S_{w}^{*} V_{w}^{*}+\mu_{s} S_{w}^{*}, \quad \mu_{v}=\left(N_{1}-N_{2}\right) \beta_{I} S_{w}^{*}, \quad\left(\mu_{s}+\mu_{I}\right)=\frac{\beta_{I} S_{w}^{*} V_{w}^{*}}{I_{w}^{*}} .
$$

Substituing the last equations into (7), it becomes

$$
\begin{aligned}
\dot{L}_{2}= & {\left[N_{2} \beta_{I} V_{w}^{*}-\left(N_{1}-N_{2}\right) \mu_{s}\right] S_{w}^{*}\left(\frac{S_{w}^{*}}{S}+\frac{S}{S_{w}^{*}}-2\right) } \\
& -N_{1} \beta_{I} S_{w}^{*} V_{w}^{*}\left(\frac{S_{w}^{*}}{S}+\frac{S}{S_{w}^{*}} \frac{V}{V_{w}^{*}} \frac{I_{w}^{*}}{I}+\frac{V_{w}^{*}}{V} \frac{I}{I_{w}^{*}}-3\right) .
\end{aligned}
$$

From the fact that the arithmetic mean is greater than or equal to the geometric mean, i.e.,

$$
\sum_{i=1}^{n} \frac{x_{i}}{n} \geq \sqrt[n]{\prod_{i=1}^{n} x_{i}}
$$

we have $\frac{S_{w}^{*}}{S}+\frac{S}{S_{w}^{*}} \geq 2$, and $\frac{S_{w}^{*}}{S}+\frac{S}{S_{w}^{*}} \frac{V}{V_{w}^{*}} \frac{I_{w}^{*}}{I}+\frac{V_{w}^{*}}{V} \frac{I}{I_{w}^{*}} \geq 3$.

Then $\dot{L}_{2}<0$, if $\left[N_{2} \beta_{I} V_{w}^{*}-\left(N_{1}-N_{2}\right) \mu_{s}\right] S_{w}^{*} \leq 0$, in fact, from (8) we can write

$$
\left[N_{2} \beta_{I} V_{w}^{*}-\left(N_{1}-N_{2}\right) \mu_{s}\right] S_{w}^{*}=N_{2}\left(k_{s}-\mu_{s} S_{w}^{*}\right)-\frac{\mu_{v} \mu_{s}}{\beta_{I}} \leq N_{2} k_{s}-\frac{\mu_{v} \mu_{s}}{\beta_{I}},
$$


and by the inequality (6), we have

$$
\left[N_{2} \beta_{I} V_{w}^{*}-\left(N_{1}-N_{2}\right) \mu_{s}\right] S_{w}^{*} \leq \frac{\mu_{v} \mu_{s}}{\beta_{I}}\left(\frac{N_{2} \beta_{I} k_{s}}{\mu_{v} \mu_{s}}-1\right) \leq 0 .
$$

Then $\dot{L}_{2}<0$ in $\mathbb{R}_{+}^{3}-\left\{P_{w}\right\}$. Besides $L_{2}\left(P_{w}\right)=0$ and $L_{2}>0$ in $\mathbb{R}_{+}^{3}-\left\{P_{w}\right\}$. Therefore the point $P_{w}$ is globally asymptotically stable.

\section{Stability analysis of model with immune response}

\section{Equilibrium Points for model (1)}

Here we show the existence of virus-free equilibrium and virus-presence equilibrium. In fact setting the system (1) equal to zero and making some calculations we can write:

$$
\begin{aligned}
S & =\frac{k_{s}}{\beta_{I} V+\mu_{s}}, \\
I & =\frac{\beta_{I} S V}{\alpha_{I} T+\left(\mu_{s}+\mu_{I}\right)}, \\
V & =\frac{N_{1}\left(\mu_{I}+\mu_{s}\right) I}{\left(N_{2} \beta_{I} S+\alpha_{v} B+\mu_{v}\right)}, \\
B & =\frac{k_{B}}{\mu_{B}-\alpha_{B} V}, \\
T & =\frac{k_{T}}{\mu_{T}-\alpha_{T} I} .
\end{aligned}
$$

These equations have biological meaning if we have $I<\frac{\mu_{T}}{\alpha_{T}}$ and $V<\frac{\mu_{B}}{\alpha_{B}}$. Now putting (11) and (12) into (13) we obtain

$$
V=\frac{k_{s} N_{1}\left(\mu_{I}+\mu_{s}\right) \beta_{I} V}{\left[N_{2} \beta_{I} k_{s}+\left(\alpha_{v} B+\mu_{v}\right)\left(\beta_{I} V+\mu_{s}\right)\right]\left[\left(\alpha_{I} T+\left(\mu_{s}+\mu_{I}\right)\right]\right.},
$$

from this equation we conclude that

$$
V=0 \text {, }
$$

or

$$
\begin{array}{r}
{\left[N_{2} \beta_{I} k_{s}+\left(\alpha_{v} B+\mu_{v}\right)\left(\beta_{I} V+\mu_{s}\right)\right]\left[\left(\alpha_{I} T+\left(\mu_{s}+\mu_{I}\right)\right]\right.} \\
=k_{s} N_{1}\left(\mu_{I}+\mu_{s}\right) \beta_{I} .
\end{array}
$$

Notice that $V=0$ implies the existence of a virus-free point which is denoted by $P_{0}$, and has the coordinates

$$
P_{0}=\left(\frac{k_{s}}{\mu_{s}}, 0,0, \frac{k_{B}}{\mu_{B}}, \frac{k_{T}}{\mu_{T}}\right) \text {. }
$$


For the existence of virus-presence equilibrium, we must show that (17) has one solution such that $V<\frac{\mu_{B}}{\alpha_{B}}$. Initially, we write (12) and (15) in terms of $V$, for this purpose, we substitute (15) into (12) to obtain

$$
c_{1} I^{2}-c_{2} I+c_{3}=0
$$

where $c_{1}=\alpha_{T}\left(\mu_{s}+\mu_{I}\right), c_{2}=\left(k_{T} \alpha_{I}+\mu_{T}\left(\mu_{s}+\mu_{I}\right)+\alpha_{T} \beta_{I} S V\right)$, and $c_{3}=\mu_{T} \beta_{I} S V$. This equation has two solutions but just one satisfies our requirements. In fact

$$
I=\frac{c_{2} \pm \sqrt{c_{2}^{2}-4 c_{1} c_{3}}}{2 c_{1}}
$$

must be real, positive and less than $\frac{\mu_{T}}{\alpha_{T}}$. First, the values are real because the expression inside of the root is always positive, that is,

$$
\begin{aligned}
{\left[k_{T} \alpha_{I}+\mu_{T}\left(\mu_{s}+\mu_{I}\right)+\alpha_{T} \beta_{I} S V\right]^{2}-4 \alpha_{T}\left(\mu_{s}+\mu_{I}\right) \mu_{T} \beta_{I} S V } \\
=\left(k_{T} \alpha_{I}\right)^{2}+2 k_{T} \alpha_{I} \mu_{T}\left(\mu_{s}+\mu_{I}\right)+2 k_{T} \alpha_{I} \alpha_{T} \beta_{I} S V \\
\quad+\left[\alpha_{T} \beta_{I} S V-\mu_{T}\left(\mu_{s}+\mu_{I}\right)\right]^{2} .
\end{aligned}
$$

Second, due to $c_{2}^{2}>c_{2}^{2}-4 c_{1} c_{3}$, for $c_{1}>0$, and $c_{3}>0$, they are real, and positive. To show that just one of them satisfies the condition $I<\frac{\mu_{T}}{\alpha_{T}}$, we see that this is true if

$$
\frac{\left[k_{T} \alpha_{I}-\mu_{T}\left(\mu_{s}+\mu_{I}\right)+\alpha_{T} \beta_{I} S V\right] \pm \sqrt{c_{2}^{2}-4 c_{1} c_{3}}}{c_{1}}<0,
$$

so the only possibility for $I$ is

$$
I=\frac{c_{2}-\sqrt{c_{2}^{2}-4 c_{1} c_{3}}}{2 c_{1}} .
$$

Then (12) and (15) are functions of $V$ and

$$
\begin{aligned}
& I=\frac{c_{2}-\sqrt{c_{2}^{2}-4 c_{1} c_{3}}}{2 c_{1}}, \\
& T=\frac{k_{T}}{\mu_{T}-\alpha_{T} I} .
\end{aligned}
$$

Finally, let us rewrite (17), and define $q$ as the polynomial:

$$
\begin{aligned}
q(V)=[ & \left.\left(N_{2} \beta_{I} k_{s}+\mu_{v} \mu_{s}+\mu_{v} \beta_{I} V\right)\left(\mu_{B}-\alpha_{B} V\right)+\alpha_{v} k_{B}\left(\beta_{I} V+\mu_{s}\right)\right] \\
& \cdot\left[\alpha_{I} T+\mu_{s}+\mu_{I}\right]-k_{s} N_{1}\left(\mu_{s}+\mu_{I}\right) \beta_{I}\left(\mu_{B}-\alpha_{B} V\right),
\end{aligned}
$$


from which we verify easily that

$$
\begin{aligned}
& q(0)=\left(1-R_{0}\right)\left(\alpha_{I} \frac{k_{T}}{\mu_{T}}+\mu_{s}+\mu_{I}\right)\left(\alpha_{v} \frac{k_{B}}{\mu_{B}}+\mu_{v}\right) \mu_{s} \mu_{B}<0, \text { if } R_{0}>1, \\
& q\left(\frac{\mu_{B}}{\alpha_{B}}\right)>0
\end{aligned}
$$

where $R_{0}$ is defined by the equation (35) in Appendix I. Then there is one solution $V$ such that $0<V<\frac{\mu_{B}}{\alpha_{B}}$. Therefore, there exists a virus-presence point $P^{*}=\left(S^{*}, I^{*}, V^{*}, T^{*}, B^{*}\right)$, for $R_{0}>1$, where:

$$
\begin{aligned}
S^{*} & =\frac{k_{s}}{\beta_{I} V^{*}+\mu_{s}}, \\
I^{*} & =\frac{c_{2}-\sqrt{c_{2}^{2}-4 c_{1} c_{3}}}{2 c_{1}}, \\
B^{*} & =\frac{k_{B}}{\mu_{B}-\alpha_{B} V^{*}}, \\
T^{*} & =\frac{k_{T}}{\mu_{T}-\alpha_{T} I^{*}},
\end{aligned}
$$

and a root of the polynomial (22) such that $0<V^{*}<\frac{\mu_{B}}{\alpha_{B}}$ and $I^{*}<\frac{\mu_{T}}{\alpha_{T}}$.

\section{Stability of virus-free equilibrium}

Here we study the stability of the virus-free point $P_{0}$

Theorem 8.1. For $R_{0} \leq 1$, the virus-free point $P_{0}$ is globally asymptotically stable.

Proof. Let $\Omega_{3}=\{(S, I, V, B, T): S>0, I \geq 0, V \geq 0, B>0, T>0\}$ and $L_{3}: \Omega_{3} \rightarrow \mathbb{R}$ be the function defined as follows:

$$
\begin{aligned}
L_{3}=a_{1} & \int_{\frac{k_{s}}{\mu_{s}}}^{S} \frac{\zeta-\frac{k_{s}}{\mu_{s}}}{\zeta} d \zeta+a_{2} I+a_{3} V+\frac{\alpha_{I}}{\alpha_{T}} a_{2} \int_{\frac{k_{T}}{\mu_{T}}}^{T} \frac{\zeta-\frac{k_{T}}{\mu_{T}}}{\zeta} d \zeta \\
& +\frac{\alpha_{v}}{\alpha_{B}} a_{3} \int_{\frac{k_{B}}{\mu_{B}}}^{B} \frac{\zeta-\frac{k_{B}}{\mu_{B}}}{\zeta} d \zeta,
\end{aligned}
$$

with the values $a_{1}=N_{1}\left(\mu_{s}+\mu_{I}\right)-N_{2}\left(\alpha_{I} \frac{k_{T}}{\mu_{T}}+\mu_{s}+\mu_{I}\right), a_{2}=N_{1}\left(\mu_{s}+\mu_{I}\right)$, and $a_{3}=\left(\alpha_{I} \frac{k_{T}}{\mu_{T}}+\mu_{s}+\mu_{I}\right)$. It is clear that $L_{3}\left(P_{0}\right)=0$ and $L_{3}>0$ in $\Omega_{3}-P_{0}$. 
Now we prove that $\dot{L}_{3}<0$. In fact

$$
\begin{aligned}
\dot{L}_{3}= & a_{1}\left(1-\frac{\frac{k_{s}}{\mu_{s}}}{S}\right)\left(k_{s}-\beta_{I} S V-\mu_{s} S\right)+a_{2}\left[\beta_{I} S V-\alpha_{I} I T-\left(\mu_{s}+\mu_{I}\right) I\right] \\
& +a_{3}\left[N_{1}\left(\mu_{s}+\mu_{I}\right) I-N_{2} \beta_{I} S V-\alpha_{v} B V-\mu_{v} V\right] \\
& +\frac{\alpha_{I}}{\alpha_{T}} a_{2}\left(1-\frac{\frac{k_{T}}{\mu_{T}}}{T}\right)\left(k_{T}+\alpha_{T} T I-\mu_{T} T\right) \\
& +\frac{\alpha_{v}}{\alpha_{B}} a_{3}\left(1-\frac{\frac{k_{B}}{\mu_{B}}}{B}\right)\left(k_{B}+\alpha_{B} B V-\mu_{B} B\right) .
\end{aligned}
$$

After some calculations, we have that

$$
\begin{aligned}
\dot{L}_{3}= & -a_{1} \mu_{s} S\left(1-\frac{\frac{k_{s}}{\mu_{s}}}{S}\right)^{2}+a_{3}\left(\alpha_{v} \frac{k_{B}}{\mu_{B}}+\mu_{v}\right) V\left[R_{0}-1\right] \\
& -\frac{\alpha_{I}}{\alpha_{T}} a_{2} \mu_{T} T\left(1-\frac{\frac{k_{T}}{\mu_{T}}}{T}\right)^{2}-\frac{\alpha_{v}}{\alpha_{B}} a_{3} \mu_{B} B\left(1-\frac{\frac{k_{B}}{\mu_{B}}}{B}\right)^{2} .
\end{aligned}
$$

Then $\dot{L}_{3}$ is negative in $\Omega_{3}-P_{0}$ if $R_{0} \leq 1$. Therefore the point $P_{0}$ is globally asymptotically stable for $R_{0} \leq 1$.

\section{Global stability of virus-presence equilibrium}

In this section, we prove the global stability of virus-presence equilibrium $P^{*}$ using a direct Lyapunov method. Let $L_{4}: \mathbb{R}_{+}^{5} \rightarrow \mathbb{R}$ be defined as follows

$$
\begin{aligned}
L_{4}= & a \int_{S^{*}}^{S} \frac{\zeta-S^{*}}{\zeta} d \zeta+b \int_{I^{*}}^{I} \frac{\zeta-I^{*}}{\zeta} d \zeta+\int_{V^{*}}^{V} \frac{\zeta-V^{*}}{\zeta} d \zeta \\
& +\frac{\alpha_{I}}{\alpha_{T}} b \int_{T^{*}}^{T} \frac{\zeta-T^{*}}{\zeta} d \zeta+\frac{\alpha_{v}}{\alpha_{B}} \int_{B^{*}}^{B} \frac{\zeta-B^{*}}{\zeta} d \zeta,
\end{aligned}
$$

where $a=\left(\frac{N_{1}\left(\mu_{s}+\mu_{I}\right) I^{*}}{\beta_{I} S^{*} V^{*}}-N_{2}\right)$, and $b=\frac{N_{1}\left(\mu_{s}+\mu_{I}\right) I^{*}}{\beta_{I} S^{*} V^{*}}$. This type of function was proposed by Goh in [12].

Theorem 9.1. The virus-presence equilibrium $P^{*}$ is globally asymptotically stable if

$$
\frac{N_{2} \beta_{I} k_{s}}{\left(\alpha_{v} \frac{k_{B}}{\mu_{B}}+\mu_{v}\right) \mu_{s}} \leq 1
$$


Remark 2. The conditions $R_{0}>1$ and $\frac{N_{2} \beta_{I} k_{s}}{\left(\alpha_{v} \frac{k_{B}}{\mu_{B}}+\mu_{v}\right) \mu_{s}} \leq 1$ give us a threshold for the parameter $\beta_{I}: \beta_{I}^{*}<\beta_{I} \leq \beta_{I}^{* *}$, where

$$
\beta_{I}^{*}=\frac{\left(\alpha_{v} \frac{k_{B}}{\mu_{B}}+\mu_{v}\right) \mu_{s}}{\left[\frac{\left(\mu_{s}+\mu_{I}\right)}{\left(\alpha_{I} \frac{k_{T}}{\mu_{T}}+\mu_{s}+\mu_{I}\right)} N_{1}-N_{2}\right] k_{s}} \text { and } \beta_{I}^{* *}=\frac{\left(\alpha_{v} \frac{k_{B}}{\mu_{B}}+\mu_{v}\right) \mu_{s}}{N_{2} k_{s}} \text {. }
$$

Remark 3. The term $\frac{N_{2} \beta_{I} k_{s}}{\left(\alpha_{v} \frac{k_{B}}{\mu_{B}}+\mu_{v}\right) \mu_{s}}$ is the average number of virions intaken by one macrophage, for more details see [13]. Therefore, condition (29) means that this average has to be at most 1 .

Proof. We start by showing that the derivative of the function $L_{4}$ defined in (28) is negative along trajectories of system (1), if (29) holds. In fact, taking the derivative of the function $L_{4}$ along trajectories of system (1), we have

$$
\begin{aligned}
\dot{L}_{4}= & a\left(1-\frac{S^{*}}{S}\right)\left(k_{s}-\beta_{I} S V-\mu_{s} S\right) \\
& +b\left(1-\frac{I^{*}}{I}\right)\left[\beta_{I} S V-\alpha_{I} I T-\left(\mu_{s}+\mu_{I}\right) I\right] \\
& +\left(1-\frac{V^{*}}{V}\right)\left[N_{1}\left(\mu_{s}+\mu_{I}\right) I-N_{2} \beta_{I} S V-\alpha_{v} B V-\mu_{v} V\right] \\
& +\frac{\alpha_{I}}{\alpha_{T}} b\left(1-\frac{T^{*}}{T}\right)\left(k_{T}+\alpha_{T} T I-\mu_{T} T\right) \\
& +\frac{\alpha_{v}}{\alpha_{B}}\left(1-\frac{B^{*}}{B}\right)\left(k_{B}+\alpha_{B} B V-\mu_{B} B\right) .
\end{aligned}
$$

From the equilibrium equations (11)-(15), we have

$$
\begin{aligned}
& k_{s}=\beta_{I} S^{*} V^{*}+\mu_{s} S^{*}, \\
& k_{T}=\mu_{T} T^{*}-\alpha_{T} T^{*} I^{*}, \\
& k_{B}=\mu_{B} B^{*}-\alpha_{B} B^{*} V^{*}, \\
& \left(\mu_{s}+\mu_{I}\right)=\frac{\beta_{I} S^{*} V^{*}-\alpha_{I} T^{*} I^{*}}{I^{*}}, \\
& \mu_{v}=\frac{\left(N_{1}-N_{2}\right) \beta_{I} S^{*} V^{*}-N_{1} \alpha_{I} T^{*} I^{*}-\alpha_{v} B^{*} V^{*}}{V^{*}} .
\end{aligned}
$$


Substituing the last equations into (30), it turns into,

$$
\begin{aligned}
\dot{L}_{4}=- & a \mu_{s} S^{*}\left(\frac{S^{*}}{S}+\frac{S}{S^{*}}-2\right)+a \beta_{I} S^{*} V^{*}\left(2-\frac{S^{*}}{S}-\frac{I}{I^{*}}-\frac{S}{S^{*}} \frac{V}{V^{*}} \frac{I^{*}}{I}+\frac{V}{V^{*}}\right) \\
& +N_{2} \beta_{I} S^{*} V^{*}\left(-\frac{I}{I^{*}}-\frac{S}{S^{*}} \frac{V}{V^{*}} \frac{I^{*}}{I}+\frac{V}{V^{*}}+\frac{S}{S^{*}}\right) \\
& +N_{1} \beta_{I} S^{*} V^{*}\left(\frac{I}{I^{*}}-\frac{V}{V^{*}}-\frac{I}{I^{*}} \frac{V^{*}}{V}+1\right) \\
& +N_{1} \alpha_{I} T^{*} I^{*}\left(\frac{V}{V^{*}}-\frac{I}{I^{*}}-1+\frac{V^{*}}{V} \frac{I}{I^{*}}\right) \\
& +b \alpha_{I} T^{*}\left(I^{*}-\frac{\mu_{T}}{\alpha_{T}}\right)\left(\frac{T}{T^{*}}+\frac{T^{*}}{T}-2\right) \\
& +\alpha_{v} B^{*}\left(V^{*}-\frac{\mu_{B}}{\alpha_{B}}\right)\left(\frac{B}{B^{*}}+\frac{B^{*}}{B}-2\right) .
\end{aligned}
$$

From (12) we have

$$
a=\left(N_{1} \frac{\left(\mu_{s}+\mu_{I}\right) I^{*}}{\beta_{I} S^{*} V^{*}}-N_{2}\right)=N_{1}-N_{2}-N_{1} \frac{\alpha_{I} T^{*} I^{*}}{\beta_{I} S^{*} V^{*}},
$$

taking the equation (33) into (32) implies

$$
\begin{aligned}
\dot{L}_{4}= & \left(N_{2} \beta_{I} V^{*}-a \mu_{s}\right) S^{*}\left(\frac{S^{*}}{S}+\frac{S}{S^{*}}-2\right) \\
& -\left(\mu_{s}+\mu_{i}\right) I^{*} N_{1}\left(\frac{S^{*}}{S}+\frac{S}{S^{*}} \frac{V}{V^{*}} \frac{I^{*}}{I}+\frac{V^{*}}{V} \frac{I}{I^{*}}-3\right) \\
& +b \alpha_{I} T^{*}\left(I^{*}-\frac{\mu_{T}}{\alpha_{T}}\right)\left(\frac{T}{T^{*}}+\frac{T^{*}}{T}-2\right) \\
& +\alpha_{v} B^{*}\left(V^{*}-\frac{\mu_{B}}{\alpha_{B}}\right)\left(\frac{B}{B^{*}}+\frac{B^{*}}{B}-2\right) .
\end{aligned}
$$

Now notice that, from the expressions in (31), the first term of (34) can be written as

$$
\begin{aligned}
N_{2} \beta_{I} S^{*} V^{*}-a \mu_{s} S^{*} & =N_{2}\left(k_{s}-\mu_{s} S^{*}\right)-\frac{\alpha_{v} B^{*}+\mu_{v}}{\beta_{I}} \mu_{s} \\
& \leq N_{2} k_{s}-\frac{\alpha_{v} B^{*}+\mu_{v}}{\beta_{I}} \mu_{s},
\end{aligned}
$$

and in view of $B^{*} \geq \frac{k_{B}}{\mu_{B}}$ and the inequality (29), we have

$$
\begin{aligned}
N_{2} \beta_{I} S^{*} V^{*}-a \mu_{s} S^{*} & \leq N_{2} k_{s}-\frac{\alpha_{v} \frac{k_{B}}{\mu_{B}}+\mu_{v}}{\beta_{i}} \mu_{s} \\
& =\frac{\alpha_{v} \frac{k_{B}}{\mu_{B}}+\mu_{v}}{\beta_{i}} \mu_{s}\left[\frac{N_{2} \beta_{I} k_{s}}{\left(\alpha_{v} \frac{k_{B}}{\mu_{B}}+\mu_{v}\right) \mu_{s}}-1\right] \leq 0 .
\end{aligned}
$$


Due to the fact that $N_{2} \beta_{I} S^{*} V^{*}-a \mu_{s} S^{*} \leq 0, V^{*}<\frac{\mu_{B}}{\alpha_{B}}$, and $I^{*}<\frac{\mu_{T}}{\alpha_{T}}$, and remembering that the arithmetic mean is greater than or equal to the geometric mean $\left(\sum_{i=1}^{n} \frac{x_{i}}{n} \geq \sqrt[n]{\prod_{i=1}^{n} x_{i}}\right)$, we have $\dot{L}_{4}<0$ in $\mathbb{R}_{+}^{5}-\left\{P^{*}\right\}$. Additionally, we have that $\dot{L}_{4}\left(P^{*}\right)=0$ and $L_{4}>0$ in $\mathbb{R}_{+}^{5}-\left\{P^{*}\right\}$. Then $P^{*}$ is globally asymptotically stable in $\mathbb{R}_{+}^{5}$.

Remark 4. If we assume in this model that the number of the virus entry into the target cells $N_{2} \beta_{I} S V$ is included into the virus loss $\mu_{v} V$, i.e., $N_{2}=0$, then we avoid the restriction (29) and the virus-presence equilibrium $P^{*}$ is globally asymptotically stable if $R_{0}>1$, with the same Lyapunov function (28) and the same proof.

\section{Discussion}

In this study, we determined the global stability of a mathematical model of a virus dynamics when there is no immune response and when there are humoral and cellular immune responses. Using the direct Lyapunov method, we showed that the virus-free point of the model with or without immune response is globally asymptotically stable, if the reproductive number of the virus is less than or equal to one, i.e., whatever the initial viral load, the virus will be cleared. In the first case, we can argue that the innate immune response is acting to stop the viral increase. Of course, in the second case, we can argue that the adaptive immunity is an effective response to control the virus and infected cells. Further, we determined the global stability of the virus-presence equilibrium whenever the viral entrance rate in the healthy cells is less than or equal to one. This condition is almost the same for the two models. The difference is that the immune response controls the rise of this viral entrance rate. In this situation does not matter how large is the initial viral load, and the result will always be a virus persistence.

\section{Acknowledgements}

M.C.G. thanks financial support, grant 2013/17264-0, from the São Paulo Research Foundation (FAPESP).

\section{Conflict of Interest}

The authors declare no conflict of interest. 


\section{References}

[1] Smith H, Leenheer P. Virus dynamics: a global analysis, SIAM Journal on Applied Mathematics, 63(4): 1313-1327, 2003.

doi: 10.1137/S0036139902406905

[2] Korobeinikov A. Global properties of basic virus dynamics models, Bulletin of Mathematical Biology, 66(4): 879-883, 2004.

doi: 10.1016/j.bulm.2004.02.001

[3] Huang G, Ma W, Takeuchi Y. Global properties for virus dynamics model with Beddington-DeAngelis functional response, Applied Mathematics Letters, 22(11): 1690-1693, 2009.

doi: 10.1016/j.aml.2009.06.004

[4] Khalid H, Yousfi N. Global stability of a virus dynamics model with cure rate and absorption, Journal of the Egyptian Mathematical Society, 22(3): 386-389, 2014.

doi: https://doi.org/10.1016/j.joems.2013.12.010

[5] Khalid H, Yang Y. Global dynamics of an age-structured viral infection model with general incidence function and absorption, International Journal of Biomathematics, 11(5): 1850065, 2018.

doi: https://doi.org/10.1142/S1793524518500651

[6] Wang X, Tao Y, Song X. Global stability of a virus dynamics model with Beddington-DeAngelis incidence rate and CTL immune response, Nonlinear Dynamics, 66(4): 825-830, 2011.

doi: 10.1007/s11071-011-9954-0

[7] Elaiw AM, AlShamrani NH. Global stability of humoral immunity virus dynamics models with nonlinear infection rate and removal, Nonlinear Analysis: Real World Applications, 26: 161 190, 2015.

doi: 10.1016/j.nonrwa.2015.05.007

[8] Elaiw AM. Global stability analysis of humoral immunity virus dynamics model including latently infected cells, Journal of biological dynamics, 9(1): 215-228, 2015.

doi: 10.1080/17513758.2015.1056846 
[9] Tsuyoshi K, Sasaki T. Global stability of pathogen-immune dynamics with absorption, Journal of biological dynamics, 4(3): 258269, 2009 .

doi: https://doi.org/10.1080/17513750903051989

[10] Khalid H, Khabouze M, Yousfi N. Dynamics of a generalized viral infection model with adaptive immune response, International Journal of Dynamics and Control, 3(3): 253-261, 2014.

doi: https://doi.org/10.1007/s40435-014-0130-5

[11] McNabb A. Comparison theorems for differential equations, Journal of mathematical analysis and applications, 119(1-2), 417-428, 1986.

doi: https://doi.org/10.1016/0022-247X(86)90163-0

[12] Goh BS. Stability in models of mutualism, The American Naturalist, 113(2): 261-275, 1979.

doi: $10.1086 / 283384$

[13] Cerón M, Yang HM. A simple mathematical model to describe antibody-dependent enhancement in heterologous secondary infection in dengue, Mathematical Medicine and Biology: A Journal of the IMA, 2018.

doi: https://doi.org/10.1093/imammb/dqy016

[14] Yang HM. The basic reproduction number obtained from jacobian and next generation matrices - A case study of dengue transmission modelling, Biosystems, 126: 52-75, 2014.

doi: 10.1016/j.biosystems.2014.10.002

[15] Yang HM, Greenhalgh D. Proof of conjecture in: The basic reproduction number obtained from jacobian and next generation matrices - A case study of dengue transmission modelling, Applied Mathematics and Computation, 265: 103-107, 2015.

doi: 10.1016/j.amc.2015.04.112 


\section{Dinámica global de las respuestas inmunes humorales y celulares a la infección por virus}

Resumen: Estudiamos la estabilidad global de un modelo de dinámica de virus teniendo en cuenta las respuestas inmunes humorales y celulares. Utilizamos un método directo de Lyapunov para obtener las condiciones suficientes para la estabilidad global de los equilibrios sin virus y con presencia de virus. Primero, analizamos el modelo sin una respuesta inmune y encontramos que si el número reproductivo del virus es menor o igual a uno, el equilibrio libre de virus es globalmente asintóticamente estable. Sin embargo, para el equilibrio en presencia de virus, la estabilidad global se obtiene si la tasa de entrada del virus en las células diana es menor que uno. Analizamos el modelo con respuestas inmunes humorales y celulares y encontramos resultados similares. La diferencia es que en el número reproductivo del virus y en la tasa de entrada del virus en las células diana, aparecen parámetros de respuestas inmunes humorales y celulares, lo que significa que la respuesta inmune adaptativa cesará o controlará el aumento de la infección.

Palabras clave: estabilidad global; respuesta inmune; método directo de Lyapunov.

\section{Dinâmica global das respostas imunes humorais e celulares à infecção viral}

Resumo: Estudamos a estabilidade global de um modelo de dinâmica de vírus com consideração das respostas imunes humoral e celular. Utilizamos um método direto de Lyapunov para obter condições suficientes para a estabilidade global dos equilíbrios sem vírus e com a presença de vírus. Primeiro, analisamos o modelo sem uma resposta imune e descobrimos que se o número reprodutivo do vírus é menor ou igual a um, o equilíbrio livre de vírus é globalmente assintoticamente estável. No entanto, para o equilíbrio na presença de vírus, a estabilidade global é obtida se a taxa de entrada do vírus nas células-alvo for menor que um. Analisamos o modelo com respostas imunes humoral e celular e encontramos resultados semelhantes. A diferença é que no número reprodutivo do vírus e na taxa de entrada do vírus nas células-alvo aparecem parâmetros de resposta imune humoral e celular, o que significa que a resposta imune adaptativa cessará ou controlará o aumento da infecção.

Palavras-chave: estabilidade global; resposta imune; método direto de Lyapunov. 


\section{Miller O. Cerón Gómez}

Associate Professor in the Department of Mathematics at Universidad de Nariño. He has a Master's degree in Mathematical sciences from the Universidad Nacional de Colombia and a PhD in Applied Mathematics from the Universidade Estadual de Campinas (Brasil). The research areas are immunology and epidemiology.

\section{Hyun Mo Yang}

Titular Professor in the Department of Applied Mathematics at Universidade Estadual de Campinas. He has Master's degree in Physics from the University of São Paulo and a PhD in Physics from the University of São Paulo. He has experience in Applied Mathematics in Biology and Medicine, working mainly in the research areas: epidemiology, physiology (immunology and allergy), agrobusiness and cancer. 